\title{
Onko tuoreen puun poltosta hyötyä maatilametsänomistajalle? Tuoreen energiarangan hankintalogistiikan ja polton kehittäminen
}

\author{
Juho Lahti ${ }^{1}$, Risto Lauhanen ${ }^{1}$, Raimo Timonen ${ }^{2}$, Jouko Laasasenaho ${ }^{3}$, Alpo Kitinoja ${ }^{4}$ \\ ${ }^{1}$ Ruoka-yksikkö, Seinäjoen ammattikorkeakoulu \\ ${ }^{2}$ Kemian laitos, Helsingin yliopisto \\ ${ }^{3}$ Metsätieteiden laitos, Helsingin yliopisto \\ ${ }^{4}$ Levón-insituutti, Vaasan yliopisto
}

Puupolttoaineet ovat Suomen tärkein uusiutuvan energian lähde, niiden osuus koko maan energian kokonaiskulutuksesta alkuvuonna 2015 oli 26\%, kun uusiutuvien energiamuotojen yhteenlaskettu osuus oli 35\%. Kiinteiden puupolttoaineiden kokonaistilavuudesta noin $40 \%$ oli metsähaketta, loput muodostuivat metsäteollisuuden sivutuotepuusta, kuten kuoresta, purusta ja teollisuuden puutähdehakkeesta.

Lämpölaitoksissa käytettävän metsähakkeen poltto-ominaisuuksien on katsottu olevan sitä parempia, mitä kuivempaa hake on. Vallitsevaan tapaan hyödyntää metsäenergiaa kuivatuksineen ja varastointeineen liittyy kuitenkin tehottomuutta. Hakkuun ja puuenergian lopullisen käytön välinen aika huomioiden vielä haketuksen jälkeinen varastointiaika lähellä käyttöpaikkaa voi olla lähellä kahta vuotta. Välivarastossa pitkään varastoidusta puusta aiheutuu yrittäjälle sitoutuneen pääoman osalta korkomenoja. Toisaalta pitkään varastossa olevan puun lämpöarvo alkaa alentua luontaisen maatumisprosessin takia. Esimerkiksi rankapuulle on siihen tienvarsivarastossa jo sitoutunut kantohinnassa, organisaatiokuluissa, hakkuussa ja metsäkuljetuksessa noin $30 € \mathrm{~m}^{-3}$ pääomaa. Viiden prosentin korkotaso aiheuttaa siis vuositasolla korkomenoja $1,5 € \mathrm{~m}^{-3}$, mistä suurien varastojen osalta aiheutuu lämpöyrittäjälle huomattava menoerä. Tämän vuoksi olisi kustannustehokkainta saada energiapuu mahdollisimman pian käyttöön nopealla kierrolla.

Kauhavan Kaukolämpö Oy:n lämpölaitoksella on kokeiltu tuoreen metsähakkeen käyttöä lämmöntuotannossa. Kyseinen 10 MW:n lämpölaitos on varustettu kondensoivalla savukaasujen pesu- ja lämmöntalteenottojärjestelmällä. Käytännön kokeissa on havaittu laitoksen yhteenlasketun lämpötehon nousseen ja hakekulutuksen vähentyneen tuoreen hakkeen käytön aikana vastaavaan kuivatettuun energiaainekseen verrattuna. Lisäteho on ollut jopa yli 30\% kattilatehoon verrattuna. Palamislämpötilat ovat korkeat ja savukaasujen häkäpitoisuus pieni.

Saavutetulle tehonlisäykselle on löydettävissä ainakin kaksi selitystä. Tuoreesta ja jäätyneestä puusta ei ole lyhyen varastoinnin aikana ehtinyt haihtua korkean energiapotentiaalin omaavia haihtuvia uuteaineita, ja toisaalta kosteata puuta poltettaessa savukaasuihin siirtyvä kosteus toimii tehokkaana lämmönsiirtäjänä savukaasuja pestäessä. Uuteaineiden polttamisessa vapautuva energia riittää korvaamaan tuoreen puun kosteuden haihduttamisen, mikäli nämä uuteaineet eivät haihdu puusta ennen polttoa ja lämmöntalteenottojärjestelmä ottaa vesihöyryn varastoiman energian talteen lämpövoimana hyödynnettäväksi.

Tuoreen metsäenergian käyttö saa aikaan muutoksia metsäenergian hinnanmuodostuksessa ja logistisissa käytänteissä sekä korjuun että varastoinnin osalta. TUOHI-hankkeessa tutkitaan, miten varastointiajat vaikuttavat uuteaineiden pitoisuuksiin ja siten lämpöarvoon. Kauhavalla toteutettu nopea energiapuun hankintaketju, moderni polttotekniikka ja savukaasujen lämmöntalteenotto mahdollistavat puuperäisten polttoaineiden hyödyntämisen entistä pienemmillä kokonaispuumäärillä, joten asialla on merki-tystä koko maan energiantuotannolle.

Asiasanat: puun hankintaketju, karsittu ranka, kotimainen energia, logistiikka, tuore hake, maatilat 


\section{Johdanto}

Kauhavan Kaukolämpö Oy:n lämpölaitoksen kondensoiva savukaasujen pesu- ja lämmöntalteenottojärjestelmän on arvioitu olevan investointina kannattava teholtaan vähintään $3 \mathrm{MW}$ :n laitoksille. Lämpöpumpun ansiosta savukaasujen lämpöenergian lämmönsiirto kaukolämpöverkkoon tapahtuu tehokkaalla lämpötila-alueella (Lahti ym. 2016).

Kuivatetun puun kosteus on yleensä $30-40 \%$, tuoreessa männyssä se voi olla jopa lähes $60 \%$. Puuteollisuuden sivuvirtana syntyvän kuorijätteen kosteus tuoreena usein ylittää 60\%. Kuivatetun puun lämpöarvon ja kaupan perusteena on yleisesti käytetty ns. tehollista lämpöarvoa saapumistilassa, joka tarkoittaa, että puun kuiva-aineen lämpöarvosta vähennetään puun sisältämän kosteuden haihduttamiseen tarvittava energia. Lämpöyrittäjä saa korvauksensa vasta, kun energiapuu on haketettu ja sen laskennallinen energiantuotto on edellä mainitulla tavalla mitattu.

Tuoreen metsäenergian käyttö muuttaa metsäenergian hinnanmuodostusta ja logistisia käytänteitä sekä korjuussa että varastoinnissa. Hakkuun ja kuivatetun hakkeen lopullisen käytön välinen aika voi olla lähes kaksi vuotta, mistä aiheutuu yrittäjälle sitoutuneen pääoman korkomenoja. Kustannustehokasta olisi käyttää energiapuu mahdollisimman pian. Lisäksi on tarpeen tutkia, miten varastointiajat vaikuttavat uuteaineiden pitoisuuksiin, polttopuun laatuun ja siten lämpöarvoon. Kauhavalla toteutettu nopea hankintaketju, moderni polttotekniikka ja savukaasujen lämmöntalteenotto mahdollistavat metsäenergian hyödyntämisen entistä pienemmillä kokonaispuumäärillä, joten asialla on merkitystä koko maan energiantuotannolle. (Lahti ym. 2016).

\section{Materiaali ja menetelmät}

Tutkimusta varten valittiin MHY Keski-Pohjanmaan Kauhavan Kaukolämpölaitokselle rankapuun toimittamista varten ostetuista leimikoista 4 mäntyvaltaista ja 4 koivuvaltaista leimikkoa. Neljä leimikkoa hakattiin talvella 2017 ja neljä alkusyksyllä 2018. Niiden puustotiedot selvitettiin metsänhoitoyhdistyksen keräämistä metsävaratiedoista ja varmistettiin vielä maastossa ennen hakkuuta. Pääpuulaji eroteltiin sekä hakkuussa että lähikuljetuksessa niin, että pääpuulajista oli käytettävissä poistuneiden runkojen koko litroissa. Koko poistumasta erotettiin tienvarsivarastoon yhtä yhdistelmäajoneuvon kuormaa vastaava näyte-erä. Leimikon kokonaispoistuma arvioitiin ForestKIT-ohjelmiston energiapuuhakkuumallin avulla. Lähikuljetusmatka mitattiin karttapalvelun avulla leimikon keskipisteestä tievarsivarastolle ja kaukokuljetus vastaavasti tienvarsivarastolta lyhintä maantiereittiä lämpölaitoksen pihavarastolle.

Näyte-erät kuljetettiin Kauhavan Kaukolämpölaitokselle, jonne tuotaessa ne punnittiin laitoksen omalla ajoneuvovaa'alla. Jotta näiden laitoksen kapasiteettiin suhteutettuna melko pienien 50 - 60 kiintokuutiometrin suuruiset näyte-erät pystyttiin hallitusti polttamaan, hankki lämpölaitos itselleen sivukuljettimen, jolla näyte-erät voitiin ohjata polttoon normaalin hakevaraston ohi.

Näyte-eristä puolet poltettiin tuoreena helmi-maaliskuussa 2017 ja puolet jätettiin kuivamaan kesäkauden yli. Tuoreen poltetut erät olivat siis haketettaessa ja poltettaessa jäisiä ja ne poltettiin haketuspäivänä. Kukin poltettava erä punnittiin haketuksen jälkeen, jolloin kuivumaan jätetyn osan alkuperäinen tuorepaino saatiin selville tuoreena poltetun ja erän kokonaispainon erotuksena. Polttamista ja palamistapahtumaa seurattiin laitoksen omin anturein ja mittarein. Lämmöntuotannon mittaamista varten käytössä tiedot verkkoon tuotetusta energiasta sekä kattilan ja lämmöntalteenoton tuotosta erikseen. Kattilan ja lämmöntalteenoton omasähkökulutus mitattiin myös, samoin kuin laitoksen oma energiankäyttö. Hakkeen kosteus määritettiin lämpölaitoksella kahden näytteen keskiarvona.

Tuoreen puun kalorimetrisen lämpöarvon ja haihtuvien aineiden tutkimiseksi kustakin näyte-erästä sahattiin kuudesta rungosta $7 \mathrm{~cm}$ paksu kiekko puun rinnankorkeudelta. Näytekiekkoja sahattiin energiapuun hankinnan eri vaiheissa - kaatopäivänä, lähikuljetuspäivänä ja haketuspäivänä - ja ne numeroitiin juoksevasti. Näytteet sahattiin käsin ja käärittiin heti alumiinifolioon, jonka ne pakattiin vakuumiin ja pakastettiin. Pakastetut näytteet toimitettiin pakastekuljetuksena Helsingin yliopistolle analysoitaviksi. 
Kuivumaan jätetyt osat näyte-eristä peitettiin kartongilla viikolla 25. Kuivattaminen onnistui kosteasta kesästä huolimatta hyvin, kosteusprosentiksi polttovaiheessa saatiin noin 26. Mänty kuivui heikommin, kosteuden jäädessä 35 - 39 prosenttiin. Tulokseen vaikuttivat tuoreen koivun selvästi alhaisempi alkukosteus ja toisaalta se, että koivusta mutkaisena muodostui harva pino ja se, että koivusta hakkuukone kuori tyviosia mäntyjä enemmän kuivumista edistäen.

\section{Tulokset}

\section{Energiarangan polttokokeet lämpölaitoksella}

Lämpölaitoksella tehtyjen polttokokeiden tulokset on eritelty puulajeittain. Tuoreena poltettua osaa näyte-erästä verrattiin vastaavaan kuivatettuun osaan ja toisaalta energiapuun teholliseen lämpöarvoon saapumistilassa. Talvella 2017 hakatuista näyte-eristä on poltettu sekä tuoreet että kuivatut osat, syksyllä 2017 hakatuista eristä vain tuoreet (Taulukko 1).

Näyte-erissä, joissa polttaminen on tehty sekä tuoreista että kuivatuista eristä, verkkoon tuotettu energia on kaikissa tapauksissa tuoreella puulla korkeampi. Lämmön talteenoton (LTO) osuus kokonaistuotosta on tuoreella männyllä noin $26 \%$ ja koivulla $17-21 \%$. Vastaavasti kuivaa puuta poltettaessa LTO:n osuus on männyllä 16 - 20\% ja koivulla $14-15 \%$. LTO-laitteiston COP-arvot (Coefficient Of Performance) eli tehokerroin oli tuoreella puulla 15 - 18 ja kuivalla 9 - 13. Kuivatettua polttoainetta poltettaessa kattilan energiantuotto oli jokseenkin sama kuin tuoreella puulla, mutta lämmöntalteenoton tuotto vastaavasti niin paljon heikompi, että kokonaistulos oli tuoreen puun poltossa parempi. Verrattaessa polttokokeiden kokonaistuloksia puuaineen teholliseen lämpöarvoon saapumistilassa laskettuna kaavalla

$$
\mathrm{Q}_{\text {net.ar }}=\mathrm{Q}_{\text {net.d }} \cdot \frac{100-\mathrm{M}_{\mathrm{ar}}}{100}-0,02441 \cdot \mathrm{M}_{\mathrm{ar}}
$$

todetaan tuoreella puulla päästyn sitä parempaan tulokseen. Kaavassa $\mathrm{M}_{\mathrm{ar}}$ tarkoittaa kosteusprosenttia ja $\mathrm{Q}_{\text {net.d }}$ lämpöarvoa puu kuiva-aineessa, jonka arvona on käytetty $19,1 \mathrm{MJ} \mathrm{kg}^{-1}$. Savukaasupesuriin kytketyn lämpöpumpun avulla voidaan siis hyödyntää tuoreessa ja kosteassa puussa olevaa latenttia energiaa. Kuivatun puut tulokset jäävät jokseenkin tehollisen lämpöarvon tasolle saapumistilassa.

Taulukko 1. Kauhavan lämpölaitoksella tehdyt polttokokeet. Osa 1=Tuore, 2=Kuivatettu. Mä= mänty ja Ko = koivu. vk= viikkoa, LTO = lämmön talteenotto, LTO:n COP = lämmöntalteenoton tehokerroin

\begin{tabular}{|c|c|c|c|c|c|c|c|c|c|c|}
\hline \multirow[b]{2}{*}{$\begin{array}{l}\text { Erän } \\
\text { tun- } \\
\text { nus }\end{array}$} & \multirow[b]{2}{*}{$\begin{array}{l}\text { Puu- } \\
\text { laji }\end{array}$} & \multirow[b]{2}{*}{ Osa } & \multirow[b]{2}{*}{$\begin{array}{l}\text { Tila- } \\
\text { vuus } \\
\mathrm{k}-\mathrm{m}^{3}\end{array}$} & \multirow[b]{2}{*}{$\begin{array}{l}\text { Kos- } \\
\text { teus \% }\end{array}$} & \multirow[b]{2}{*}{$\begin{array}{l}\text { Va- } \\
\text { ras- } \\
\text { tointi, } \\
\text { vk }\end{array}$} & \multirow[b]{2}{*}{$\begin{array}{l}\text { Lämpöarvo } \\
\text { MWh · m-3 } \\
\text { saapumis- } \\
\text { tilassa }\end{array}$} & \multicolumn{3}{|c|}{$\begin{array}{c}\text { Tuotettu lämpöenergia, MWh · } \\
\text { m}^{-3}\end{array}$} & \multirow[b]{2}{*}{$\begin{array}{l}\text { LTO:n } \\
\text { COP }\end{array}$} \\
\hline & & & & & & & Yhteensä & Kattila & LTO & \\
\hline \multirow[t]{2}{*}{ 076J } & Mä & 1 & 26.0 & 58.0 & 4 & 1.710 & 2.124 & 1.583 & 0.541 & 16.1 \\
\hline & & 2 & 24.3 & 39.4 & 39 & 1.817 & 1.928 & 1.548 & 0.379 & 12.8 \\
\hline \multirow[t]{2}{*}{$058 \mathrm{~F}$} & Ко & 1 & 18.7 & 45.0 & 4 & 2.354 & 2.561 & 2.011 & 0.549 & 15.1 \\
\hline & & 2 & 20.5 & 26.6 & 42 & 2.370 & 2.286 & 1.974 & 0.312 & 8.9 \\
\hline \multirow[t]{2}{*}{ 030L } & Ко & 1 & 14.1 & 44.5 & 5 & 2.382 & 2.580 & 2.130 & 0.449 & 10.5 \\
\hline & & 2 & 10.5 & 25.0 & 33 & 2.540 & 2.166 & 1.996 & 0.170 & 9.2 \\
\hline \multirow[t]{2}{*}{ 078C } & Mä & 1 & 31.6 & 57.3 & 5 & 1.748 & 2.028 & 1.497 & 0.531 & 14.7 \\
\hline & & 2 & 32.5 & 35.1 & 38 & 1.804 & 1.774 & 1.493 & 0.281 & 11.7 \\
\hline 058F2 & Mä & 1 & 26.4 & 56.4 & 8 & 1.800 & 2.094 & 1.559 & 0.534 & 16.8 \\
\hline 071J & Mä & 1 & 27.8 & 60.9 & 13 & 1.545 & 1.877 & 1.367 & 0.510 & 18.2 \\
\hline 030A & Ko & 1 & 22.2 & 43.7 & 10 & 2.418 & 2.386 & 1.880 & 0.506 & 15.6 \\
\hline $114 \mathrm{~F}$ & Ko & 1 & 24.0 & 46.9 & 11 & 2.251 & 2.353 & 1.847 & 0.507 & 15.5 \\
\hline
\end{tabular}


Syksyllä kaadettujen puiden varastointiaika venyi talvikaatoisia pidemmäksi. Niidenkin osalta mänty tuotti tuoreena paremmin kuin lämpöarvoon saapumistilassa perustuva laskennallinen tuotto olisi ollut. Koivulla sen sijaan jäätiin saapumistilan lämpöarvon tasolle. Kuva 1 esittää energian kokonaistuoton riippuvuutta varastointiajasta. Käytettävissä oli vasta 12 polton tulokset, joten tilastollista tarkastelua ei voi pitää luotettavana, vain vasta suuntaa-antavana. Luotettavampi tulos saadaan, kun kuivamaan jätetyt syyskaatoisten erien osat poltetaan syksyllä 2018.

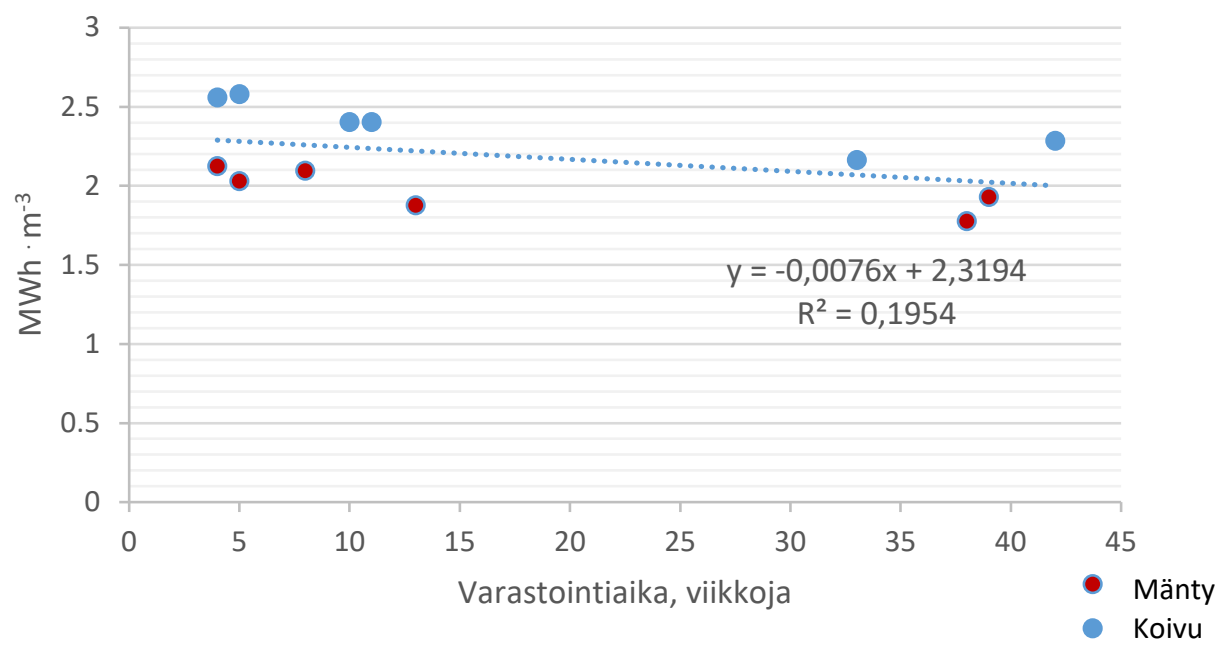

Kuva 1. Polttokokeissa tuotettu energiamäärä suhteessa varastointiaikaan $\mathrm{MWh} \mathrm{m}^{-3}$

\section{Hankintakustannukset}

Metsänomistajan kannalta tuorehakkeen hankintaketju tienvarsivarastosta lämpölaitokselle on nopea. Liikenne vähenee paikallisteillä, kun autohakkurit kiertävät vain lämpölaitokselta toiselle. Tienvarsivarastoinnin aika on lyhyt, jolloin hyönteistuhovaara vähenee eikä ravinteita liukene varastoista ojiin eikä maaperään.

Eteläpohjalaisessa ensiharvennusmännikössä hankintakustannukset kiintokuutiota kohden olivat 50\% kostealle tuorehakkeelle 43,5€ (23,4€ $\left.\mathrm{MWh}^{-1}\right)$ ja kuivalle hakkeelle 51,0 $€\left(26,2 € \mathrm{MWh}^{-1}\right.$, kosteus $35 \%$ ). Vastaavasti koivikossa kustannukset olivat 44,6€ tuoreelle kiintokuutiolle (45\% kosteus, 19,0 $€$ $\mathrm{MWh}^{-1}$ ) ja 48,0 € kuivatetulle (20,4€ $\mathrm{MWh}^{-1}$, kosteus 35\%).

Laitilan (2005) mallilla laaditut esimerkkilaskelmat osoittivat, että tuorehakkeen hankinta oli 7-8 $€ \mathrm{~m}^{-3}$ edullisempaa kuin perinteisen kuivatetun hakkeen. Jos käyttöpaikkahaketuksen kustannus maksaisi $4 €$ $\mathrm{m}^{-3}$ oletusarvoa enemmän, niin kustannusero olisi 3-4€ $\mathrm{m}^{-3}$, mutta edelleen tuorehakkeen hyväksi. Pääoman sitoutumisen takia hakkuukustannus on noin $0,1 € \mathrm{~m}^{-3}$ ja metsäkuljetuskustannus $0,1 € \mathrm{~m}^{-3}$ suurempi kuivan hakkeen hankinnassa kuin tuorehakkeen hankinnassa. Tienvarsivarastojen peittäminen maksaa $1,0 € \mathrm{~m}^{-3}$.

Vielä kymmenen vuotta sitten kuivan puun haketus oli noin 1,0 $€ \mathrm{~m}^{-3}$ kalliimpaa kuin tuoreen puun. Nykyisellä teknologialla tätä eroa ei ole. Tuoreen energiarangan kaukokuljetus on edullisempaa kuin tienvarsivarastossa kuivuneen hakkeen eron ollessa $1,2 € \mathrm{~m}^{-3}$. Keskeisin kustannusero johtuu siitä, että tienvarressa kuivatun rangan haketus on noin $3 €$ kalliimpaa kuin tuoreen rangan käyttöpaikkahaketus.

Leimikkotasolla poistuman rungon keskijäreys oli merkittävin yksittäinen kustannustekijä puunhankinnassa. Mitä pienempiä runkoja hakataan, sitä hitaammin kertyy tilavuutta ja sitä enemmän hakkuutyö 
maksaa. Edelleen, mitä suurempi on leimikon koko eli kokonaishakkuukertymä, sitä alhaisemmat ovat korjuun yksikkökustannukset. (Laitila 2005, Lauhanen ym. 2007, Lahti ym. 2016, Laitila ym. 2017).

Mitä pitempi metsäkuljetusmatka (m), sitä kalliimpaa metsäkuljetus on kuljetettua kiintokuutiometriä kohti. Myös, mitä pitempi kaukokuljetusmatka $(\mathrm{km})$ on metsävarastolta lämpölaitokselle, sitä enemmän kaukokuljetus maksaa kuutiometriä kohti, vaikka sen hinta kilometriä kohden laskee matkan pidetessä. (Laitila 2005, Lauhanen ym. 2007, Lahti ym. 2016, Laitila ym. 2017).

Tuorehakkeen hankintakustannukset olivat siis alhaisemmat kuin kuivan pienpuuhakkeen. Laitila ym. (2017) ovat päätyneet mallilaskelmissaan saman suuntaisiin tuloksiin Rovaniemen olosuhteissa. Tuorehakkeen hankintakustannus oli siellä $41,1 € \mathrm{~m}^{-3}$ ja kuivahakkeen vastaavasti 45,1 $€ \mathrm{~m}^{-3}$. Laitilan ym. (2016, 2017) laskelmat ovat tämän tutkimuksen tavoin mallinnettuja esimerkkejä.

Etelä-Pohjanmaalla suuret sika- ja broileritilat käyttävät paljon energiapuuta. Osa niistä ostaa energiarankaa metsäyhtiöiden varastoista, koska suurilla voimalaitoksilla edullinen kivihiili on vähentänyt metsäenergian käyttöä viime vuosina. Hyvä kysyntä on pitänyt energiarangan hinnan Etelä-Pohjanmaalla muuta maata korkeammalla vuosina 2016 - 2017. Esitetyt laskelmat tehtiin ilman hintoihin kohdistuneita tukia, joilla on vaikutusta energiapuukaupan osana (ks. Lauhanen ym. 2014). Suomessa puuta mitataan ja myydään kuorellisina kiintokuutiometreinä, jos ei muuta sovita (Lauhanen ym. 2014). Kun hankintakustannukset laskevat, on energiapuun ostajan maksukyky puusta parempi kuin kuivahakeketjussa. Puun hinta on kuitenkin aina ostajan ja myyjän välinen asia, eikä tutkimus ota kantaa energiapuun hinnoitteluun (ks. Laitila ym. 2017).

\section{Haihtuvat aineet}

Haihtuvien aineiden merkitystä on tutkittu alustavasti näytekiekkojen eri osista (sydänpuu, mantopuu, sisä- ja ulkokuori) otetuilla näytteillä. Näytteistä haihtuvien aineiden määrän ajallista käyttäytymistä on tarkkailtu kaasukromatografisesti ja aineita tunnistettu massaspektrometrisesti (GC-MS). Merkittävimpien männyn ja koivun monoterpeenien ( $\alpha$-pineeni ja 3-kareeni) haihtumista hakelastuista on kuvattu kuvassa 2. Rangasta tapahtuva diffuusion kontrolloima haihtuminen on suuremman massan vuoksi hitaampaa. Haihtumiseen vaikuttavat myös olosuhteet, mutta haihtuvien aineiden korkea lämpöarvo vaikuttaa polttoaineen energiasisältöön heikentävästi samoin kuin se, että puun kaadon jälkeen lahoaminen alkaa heti mikrobien käyttäessä puuta hyväkseen elintoiminoissaan.

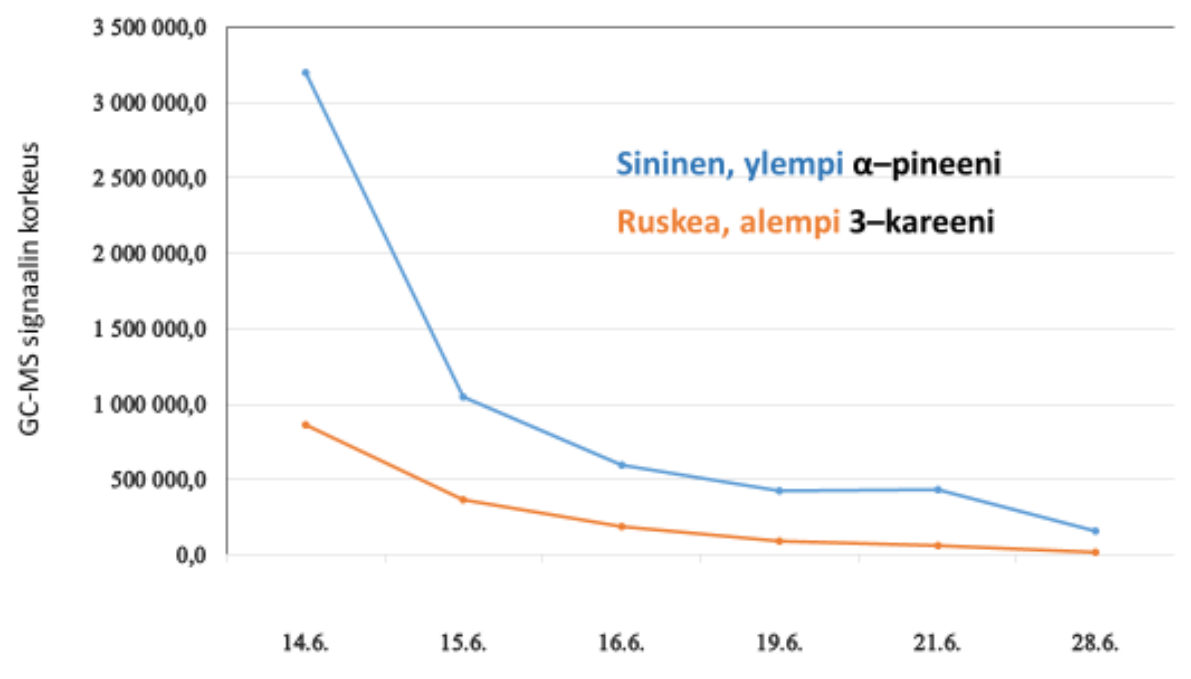

Kuva 2. Haihtuvien aineiden poistumisnopeus lastuista GC-MS menetelmällä mitattuna kesäkuussa 2017. Monoterpeenien määrä puoliintuu hakelastussa noin vuorokaudessa, rangassa hitaammin diffuusion johdosta. 


\section{Tulosten tarkastelu}

Polttokokeet osoittivat tuoreen energiarangan olevan kuivattua puuta paremman energialähteen laitoksella, joka pystyy ottamaan talteen savukaasujen vesihöyryyn sitoutuneen energian. Tuloksia tarkasteltaessa tulee muistaa, että Kauhavan kaukolämpölaitos on tarkoitettu tuotantoon eikä tutkimukseen ja että tulokset ovat sovellettavissa vain samanlaiseen lämpölaitosratkaisuun.

Tuore hake poltettiin jäisenä, eikä sulamiseen kuluvaa energiaa ole otettu laskemissa huomioon. Todelliseen tuoreen puun kalorimetriseen lämpöarvoon se kuuluisi, mutta koska kuivatuissakin erissä oli vielä runsaasti jäätynyttä vettä, vain erotus tulisi huomioida. Toinen tuloksista huomioitta jätetty energia on lauhdeveteen jäävä lämpö.

Analyysit tuoreen puun kalorimetrisesta lämpöarvosta ja haihtuvien aineiden merkityksestä ovat vielä joulukuussa 2017 kesken. Alustavien tulosten perusteella haihtuminen hakkeesta voi olla niin nopeaa, että haihtuvien aineiden merkitys polttokokeiden mittakaavassa ei tule esille. Todennäköisesti diffuusiona tapahtunut haihtuminen on jo alentanut syyskaatoisen puun lämpöarvoa. Haihtumisnopeus onkin riippuvaista lämpötilasta, oletettavasti talvikaatoisessa jäisessä puussa 4 - 5 viikon kuluessa kaadosta ne suurelta osin olivat tallessa. Kuitenkin jo itse haketus ja sitä seuraava lyhyt varastointi voivat aiheuttaa näiden aineiden merkittävän haihtumisen. Uute-aineiden haihtumista kuoresta ovat tutkineet myös Lappi ym. (2014). Tulosten perusteella rungosta irrotetusta kuoresta uuteaineiden määrä puolittuu varastoitaessa noin viikossa. Ekmanin (2000) mukaan kuusen mantopuun uuteainepitoisuus laskee varastoinnin aikana nopeasti, kun taas sydänpuussa se pysyi jokseenkin vakaana. Kauhavan lämpölaitoksella puuta ei varastoida hakkeena pitkään, vaan hake siirretään välittömästi laitoksen katettuun varastoon, josta se siirtyy kuljettimilla kattilalle 1 - 3 vuorokauden kuluessa kaukolämmöntarpeesta riippuen.

Kuivan puun lämpöarvoa alensi todennäköisesti jo puun lahoamisen aiheuttama kuiva-ainetappio ainakin männyllä, jonka kosteus vielä polttovaiheessa oli lähes 40\%. Kärkkäisen (2003) mukaan kuiva-ainetappio pyöreässä puussa on kasvukauden aikana 6 - 7\%. Uusimmissa energiapuuta koskevissa tutkimuksissa energiarangalla kuiva-ainetappion on todettu olevan noin $0,2-0,9 \%$ kuukaudessa (Routa ym. 2017).

\section{Johtopäätökset}

Tuorehaketta käytettiin polttoaineena kuntatason lämpölaitoksella, jonka kattilateho oli $10 \mathrm{MW}$. Laitoksen tuottamien savukaasujen puhdistustekniikaksi oli valittu pesuri, johon oli kytketty lämpöpumppu savukaasun vesihöyryn sisältämän energian talteen ottamiseksi. Tällä kokoonpanolla tuorehake tuottaa lämpöä kiintokuutiometriä kohden tehokkaammin kuin kuivahake.

Polttolaitosten pienhiukkaspäästöjä koskevien uusien määräysten voimaatulo ohjaa lähitulevaisuudessa investointeja. TUOHI-hankkeen alustavien tulosten perusteella savukaasupesuri on kustannustehokas vaihtoehto suuremmille, yli 3 MW:n lämpövoimaloille.

Tuorehakkeen hankintavarmuus ei varastojen pienuuden vuoksi ole kuivatetun energiapuun luokkaa. Esimerkiksi kelirikkoaikojen puskurivarastoksi on käytettävissä oltava kuivatettua energiapuuta tai kuorta. Tuorehakekonsepti pystyy tarjoamaan nopeimman ja toimitusvarmimman hankintaketjun laitokselle saakka. Rangasta tehdyn tuorehakkeen käyttö lisäisi ensiharvennuspuun kysyntää ja pienentäisi pääoman sitoutumisen vähenemisen kautta lämpöyrittäjien riskiä. Kuivatuksen jäädessä pois rahan kierto nopeutuu ja korkomenot pienenevät. Kauppa lämpöyrittäjien ja lämpölaitosten välillä on kuitenkin muutettava kiintokuutioperusteiseksi, koska teholliseen lämpöarvoon saapumistilassa perustuva nykyinen laskentamalli ei tuoreen puun poltossa vastaa oikeata lämmöntuotantopotentiaalia. 
Maatiloilla, kotitalouksissa ja perinteisissä lämpöyrittäjäkohteissa, joissa lämmöntalteenottoa ei ole käytettävissä, on edelleen käytettävä kuivaa metsähaketta ja polttopuuta. Jatkossa on tarpeen selvittää, voidaanko suurilla maatiloilla soveltaa kattilaratkaisuja, jotka soveltuvat tuorehakkeen ja peltobiomassojen polttoon. Energiapuuharvennukset ovat tärkeä osa nuorten metsien ja maatilan omaisuuden hoitoa, samalla turvataan tulevaisuuden tukki- ja kuitupuukertymät. Kaikki tuorehakkeen käytön edut eivät ole suoraan euroiksi muunnettavissa. Tuorehakkeen hankinta torjuu osaltaan metsien hyönteistuhovaaraa, koska energiapuuta ei enää varastoida metsissä. Uusi teknologia pitää maaseututeiden varret hakejäämistä siistinä. Lisäksi tarpeeton autohakkuriliikenne jää pois huonosti kantavilla paikallisteillä.

\section{Kiitokset}

Kiitos Kauhavan Kaukolämpö Oy:n toimitusjohtaja Ari-Matti Mattilalle ja käyttöpäällikkö Juho Lahtiselle sekä Metsähoitoyhdistys Keskipohjan metsänasiantuntija Jani Puronvarrelle tutkimuksen mahdollistamisesta. Kiitokset Etelä-Pohjanmaan ELY-keskukselle ja yksityisille hankerahoittajille MannerSuomen maaseutuohjelmassa. MMT Juha Laitila (Luke) antoi hyviä neuvoja TUOHI-hankkeelle ja Tapio Syrjälä (hankkeen projektipäällikkö 1.6.2018 lähtien) auttoi käsikirjoituksen oikolukemisessa ja Kari Hartonen (HY:n Kemian laitos) haihtuvien aineiden mittauksessa.

\section{Kirjallisuusviitteet}

Ekman, R. 2000. Resin during storage and in biological treatment. Teoksessa: Back, E.-L. (toim.). Pitch Control, Wood resin and Deresination. Atlanta, USA: Tappi Press. s. 37-76.

Kärkkäinen, M. 2003. Puutieteen perusteet. Hämeenlinna: Kustannusosakeyhtiö Metsälehti. Karisto Oy. 451 s.

Lahti, J., Lauhanen, R. \& Kitinoja, A. 2016. Tuoreen puun polttaminen - uusi avaus. Teoksessa: Junell, P., Heikkilä, A., Päällysaho, S. \& Saarikoski, S. (toim.). Hyvinvointia ja innovaatioita monialaisesti ja raja-aitoja madaltaen. Katsaus Seinäjoen ammattikorkeakoulun toimintaan 2016. Seinäjoen Ammattikorkeakoulun julkaisusarja A. Tutkimuksia 25. s. 451-465.

Laitila, J. 2005. Pienpuuhakkeen hankintakustannuslaskuri. Excel-ohjelmisto. Metsäntutkimuslaitos.

Laitila, J., Lehtonen, E., Ranta, T., Anttila, P., Rasi, S. \& Asikainen, A. 2016. Procurement costs of cereal straw and forest chips for biorefining in South-East Finland. Silva Fennica vol. 50 article id 1689. https://doi.org/10.14214/sf.1689

Laitila, J., Ahtikoski, A., Repola, J. \& Routa, J. 2017. Pre-feasibility study of supply systems based on artificial drying of delimbed stem forest chips. Silva Fennica vol. 51 article id 5659. https://doi.org/10.14214/sf.5659

Lappi, H., Nurmi. J. \& Läspä, O. 2014. Decrease in extractives of tree bark during storage. Forest Refine info sheet. 4 p. [28.8.2017: http://biofuelregion.se/wp-content/uploads/2017/01/3_11_IS_2014-08-11_

Decrease_in_Extractives_Lappi_Nurmi_Laspa.pdf]

Lauhanen, R., Laitila, J., Laurila, J. \& Asikainen, A. 2007. Pienpuuhakkeen hankintakustannukset EteläPohjanmaan tavoite 2 -alueella. Teoksessa: Lauhanen, R. \& Laurila, J. (toim.) Bioenergian hankintalogistiikka. Tapaustutkimuksia Etelä-Pohjanmaalta. Seinäjoen ammattikorkeakoulun julkaisuja B33. s. 49-67.

Lauhanen, R., Ahokas, J., Esala, J., Hakonen, T., Sippola, H., Viirimäki, J., Koskiniemi, E., Laurila, J. \& Makkonen, I. 2014. Metsätoimihenkilön energialaskuoppi. Seinäjoen ammattikorkeakoulun julkaisusarja C. Oppimateriaaleja 6. 167 s.

Routa, J., Kolström, M. \& Sikanen, L. 2017. Dry matter losses and their economic significance in forest energy procurement. Submitted to International Journal of Forest Engineering. 